for the detection of human cytomegalovirus amplicons by sandwich hybridization. Anal. Biochem. 253:180-189.

22.Zammatteo, N., C. Girardeaux, D. Delforge, J.-J. Pireaux and J. Remacle. 1996. Amination of polystyrene microwells: Application to the covalent grafting of DNA probes for hybridization assays. Anal. Biochem. 236:85-94.

22.Beach, R.C. 1981. The unified graphics system for Fortran 77 programs manual. Stanford, CA.

The authors would like to thank ID Biomedical (Bothell, WA, USA) for the material support. They also would like to thank I. Ernest for critical revision of the manuscript. Address correspondence to Stéphanie Warnon, Facultés Universitaires Notre-Dame de la Paix, Laboratoire de Biochimie cellulaire, 61 rue de Bruxelles 5000 Namur, Belgium. Internet: stephanie. warnon@fundp.ac.be

Received 10 November 1999; accepted 22 February 2000.

S. Warnon, N. Zammatteo, I. Alexandre, C. Hans and J. Remacle

Facultés Universitaires Notre-Dame de la Paix Namur, Belgium

\section{Application of DNA Topoisomerase-Activated Adapters to Riboprobe Synthesis}

BioTechniques 28:1160-1165 (June 2000)

\section{ABSTRACT}

Topoisomerase-activated adapters for rapid incorporation of the $T 7$ promoter into PCR products were made by hybridizing synthetic oligonucleotides and activating vaccinia DNA topoisomerase I. The adapters were used to incorporate the T7 promoter sequence into PCR products amplified from cDNA and genomic DNA. Mod- ified PCR products were used as templates to synthesize digoxigenin-labeled sense and cRNA probes by in vitro transcription with phage T7 RNA polymerase. The red/green cones were labeled by the antisense probe, but no specific signal was produced by the sense probe. These results demonstrate that topoisomerase-activated adapters provide a powerful and convenient tool for the rapid modification of PCR products.

\section{INTRODUCTION}

Recent advances in gene discovery technology and the human genome project have revealed thousands of new sequences, which are being characterized for tissue- or disease-specific expression. These analyses involve Northern blotting, RNase protection and in situ hybridization techniques that often rely on the use of riboprobes generated from DNA templates by in vitro transcription (IVT). Traditional approaches to template preparation for IVT include subcloning the DNA of interest into a plasmid vector with an appropriate RNA polymerase promoter (6) or incorporating the promoter sequences during PCR amplification with primers carrying the promoter sequence at their 5' ends (5).

While both techniques seem to be reliable and have certain advantages, the first one requires lengthy and laborious steps to transform bacterial cells and identify the right recombinant clones, plasmid DNA purification and linearization. The second one requires a synthesis of primers with 5'-end extensions containing RNA polymerase promoters for every DNA of interest, in addition to regular gene-specific primers, a method that may be time and cost inefficient over the long run.

This report introduces a novel technique to quickly generate templates for IVT from PCR products. The method is based on the use of topoisomerase-activated adapters containing the promoter for T7 RNA polymerase. The adapters are hybridized oligonucleotides that have been cleaved and activated by vaccinia DNA topoisomerase I. This enzyme has unique properties that allow cleavage of dsDNA at a CCCTT recognition site, form a covalent bond with the substrate and religate it to an acceptor DNA through a 5'-hydroxyl group 
$(7,8)$. Based on these properties, several applications for molecular cloning and polynucleotide synthesis were proposed by Shuman (9). In addition, a number of plasmid vectors for cloning PCR products was developed by Invitrogen (Carlsbad, CA, USA) (4). The properties of vaccinia DNA topoisomerase could be used to design a family of topoisomerase-activated adapters for various modifications of PCR products with no need for subcloning. This new method of molecular cloning using topoisomerase-activated adapters is illustrated by the incorporation of the $\mathrm{T} 7$ promoter into PCR products.

\section{MATERIALS AND METHODS}

\section{Tissues}

Monkey eyes were kindly provided by Drs. Donald Heistad and Donald Piegors, Cardiovascular Division, Department of Internal Medicine at the University of Iowa. Adult cynomolgus monkeys (Macaca fascicularis) were euthanized with an overdose of sodium pentobarbital $(100 \mathrm{mg} / \mathrm{kg})$ administered intravenously. The eyes were enucleated within 40 min postmortem, and retinal punches were frozen immediately in liquid nitrogen for RNA isolation. The posterior eye cups were fixed in $4 \%$ paraformaldehyde in 0.1 M PBS (pH 7.4) for $2 \mathrm{~h}$ at $4^{\circ} \mathrm{C}$ for in situ hybridization. All procedures for the care and handling of animals complied with both federal and University of Iowa policies.

\section{RNA Isolation and cDNA Synthesis}

Total RNA from monkey retina was isolated by isopycnic centrifugation (2). One microgram total RNA was primed with oligo(dT) ${ }_{12-18}$ and reverse transcribed using SUPERSCRIPT IITM $^{\mathrm{TM}}$ RNase $\mathrm{H}^{-}$reverse transcriptase (Life Technologies, Rockville, MD, USA) in a $20-\mu \mathrm{L}$ reaction volume.

\section{Oligonucleotides}

Single-strand oligonucleotides T7TOPO (5'-TAATACGACTCACTATAGGGACCCTTGGTGCACCA-3'), ASTOPO (5'-AGGGTCCCTAT-3'), T7 primer (5'-TAATACGACTCACTATAGGGA-3') and gene-specific primers were synthesized by Ransom Hill Bioscience (Ramona, CA, USA) and Integrated DNA Technologies (Coralville, IA, USA). Sense (5'-GTACCACCTCACCAGTGTCT- $3^{\prime}$ ) and antisense (5'AAATGATGGCCAGAGACCAG-3') primers were used to generate 288-bp PCR products homologous to human green cone pigment mRNA (GenBank $^{\circledR}$ accession no. NM_000513, positions 156-443). Two species of PCR products-long and medium wavelength-sensitive monkey cone pigment cDNA fragments, which are highly homologous to human red and green cone pigment $\mathrm{cDNAs}$ - were amplified with these primers from oligo(dT)-primed first-strand monkey retina cDNA. In addition, sense (5'-GAAGCACATGTCTTTAATGTC-3') and antisense (5'GAACTAACATTAATACACATCAC$\left.3^{\prime}\right)$ primers were used to amplify a 483-bp fragment of the human PRL-1 gene (GenBank accession no. AF051160, positions 10021-10503) from human genomic DNA.

\section{PCR}

PCR amplifications were performed in $50-\mu \mathrm{L}$ reactions consisting of $200 \mu \mathrm{M}$ dNTPs (Clontech Laboratories, Palo Alto, CA, USA), $0.3 \mu \mathrm{M}$ each primer, $1 \times$ PCR buffer $[10 \mathrm{mM}$ Tris- $\mathrm{HCl}(\mathrm{pH}$ $8.3), 50 \mathrm{mM} \mathrm{KCl}, 1.5 \mathrm{mM} \mathrm{MgCl}$ and $0.01 \%(w / v)$ gelatin] and $2.5 \mathrm{U}$ Taq DNA polymerase (Fisher Scientific, Pittsburgh, PA, USA) with the following program: 3 min at $95^{\circ} \mathrm{C} ; 30$ cycles of 30 s at $95^{\circ} \mathrm{C}, 30 \mathrm{~s}$ at $56^{\circ} \mathrm{C}, 30 \mathrm{~s}$ at $72^{\circ} \mathrm{C}$ and a final extension for $2 \mathrm{~min}$ at $72^{\circ} \mathrm{C}$. The amplification of the PRL-1 gene fragment was performed in 35 cycles with the annealing temperature at $58^{\circ} \mathrm{C}$ and 50 ng human genomic DNA as template. The amplification from monkey retina cDNA was started with $1 \mu \mathrm{L}$ reverse transcription reaction as template and was performed in 30 cycles. PCR products were purified with the QIAquick $^{\mathrm{TM}} \mathrm{PCR}$ purification kit (Qiagen, Valencia, CA, USA) for IVT, and automated sequencing was carried out at the University of Iowa DNA facility.

\section{Topoisomerase-Activated T7 Adapters}

Synthetic oligonucleotides T7TOPO and ASTOPO (12 $\mu \mathrm{M}$ each) were hybridized in $0.25 \mathrm{M} \mathrm{NaCl}$ solution by heating to $65^{\circ} \mathrm{C}$ for $5 \mathrm{~min}$ followed by slow cooling to $25^{\circ} \mathrm{C}$ at a rate of

\section{Hybridization of T7TOPO and ASTOPO: \\ TAATACGACTCACTATAGGGACCCTTGGTGCACCAagggtcoctat

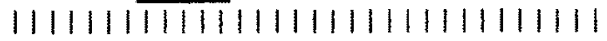 \\ tatccctgggaACCACGTGGTTCCCAGGGATATCACTCAGCATAAT}

Activation with topoisomerase I:

TAATACGACTCACTATAGGGACCCTT-Topo
\|\|\|\|\|\|$\|$
tatccetggga

GGTGCACCA

\|\|\|\|$\|$

ACCACGTGG agggtccetat

\|\|\|\|\|\|$\|$

Topo-TTCCCAGGGATATCACTCAGCATAAT

Figure 1. Adapter sequence hybridization activated with vaccinia DNA topoisomerase I for introduction of T7 promoter into PCR products. The hybridization occurs as a result of self-complementarity of T7TOPO (uppercase letters) at the 3 '-end and complementarity of ASTOPO (lower case letters) to positions $15-25$ of T7TOPO; the nicks are formed in both strands between T7TOPO and ASTOPO. The recognition set for vaccinia DNA topoisomerase I is underlined. 
$0.5^{\circ} \mathrm{C} / \mathrm{min}$. The activation of the adapters was performed by incubation of $1.25 \mu \mathrm{L}$ hybridized oligonucleotides with 2.5 U vaccinia DNA topoisomerase I (Epicentre Technologies, Madison, WI, USA) in $50 \mathrm{mM}$ Tris$\mathrm{HCl}$ buffer $(\mathrm{pH} 7.5)$ at $37^{\circ} \mathrm{C}$ for $15 \mathrm{~min}$. The activated adapters were stored in $50 \%$ glycerol at $-20^{\circ} \mathrm{C}$ until used.

\section{Incorporation of T7 Promoter Sequence into PCR Products}

Three microliters unpurified PCR products were incubated with $2 \mu \mathrm{L}$ activated adapters at $25^{\circ} \mathrm{C}$ for $5 \mathrm{~min}$. One microliter reaction mixture was used as a template in two separate PCR amplifications with $\mathrm{T} 7$ primer and sense or antisense gene-specific primers. The reamplification generated PCR products carrying the $\mathrm{T} 7$ promoter either on the $5^{\prime}$ end or the $3^{\prime}$ end. The products were resolved on a $3 \%$ SFR $^{\mathrm{TM}}$ agarose
(Amresco, Solon, OH, USA) gel in TBE buffer and visualized with ethidium bromide.

\section{In Vitro Transcription}

Digoxigenin (DIG)-labeled cRNA probes were transcribed in vitro using phage T7 RNA polymerase and purified PCR products containing the T7 promoter as templates $(6.5 \mu \mathrm{L} / 20-\mu \mathrm{L}$ reaction). The reaction buffer and conditions were used according to the manufacturer's recommendations (Roche Molecular Biochemicals, Indianapolis, IN, USA). Labeled RNA transcripts were precipitated with $\mathrm{LiCl}$ and resuspended in diethylpyrocarbonate (DEPC)-treated water. DIG-labeled control RNA was used as a standard to estimate the yields of reactions with anti-DIG antibodies conjugated to alkaline phosphatase using NBT/BCIP as a substrate in a dot-blotting assay as previously de- scribed (3). All reagents were from Roche Molecular Biochemicals.

\section{In Situ Hybridization}

Transverse cryostat sections $(7 \mu \mathrm{m})$ of monkey retina were hybridized with DIG-labeled cRNA probes for red/ green cone pigment cDNA using a protocol with some modifications (3). The sections were permeabilized with Proteinase K $(5 \mu \mathrm{g} / \mathrm{mL}$; Roche Molecular Biochemicals) and washed in PBSTween ${ }^{\circledR} 20(0.1 \%$ v/v). Hybridization was carried out overnight at $60^{\circ} \mathrm{C}$ with $1 \mu \mathrm{g} / \mathrm{mL}$ cRNA probe in $50 \%$ formamide, $5 \times$ standard saline citrate (SSC), $1 \mathrm{mg} / \mathrm{mL}$ yeast RNA, $1 \times$ Denhardt's solution, $0.1 \%$ Tween $20,0.1 \%$ CHAPS and $5 \mathrm{mM}$ EDTA. The slides were repeatedly washed in $50 \%$ formamide, $4 \times$ SSC, $1 \%$ SDS and in $50 \%$ formamide and $2 \times \mathrm{SSC}$ at $65^{\circ} \mathrm{C}$. Binding of DIG-labeled cRNA probes was 


\section{Short Technical Reports}

detected with anti-DIG antibodies conjugated to alkaline phosphatase using NBT/BCIP as a substrate.

\section{RESULTS AND DISCUSSION}

Synthetic oligonucleotides were designed to generate topoisomerase-activated T7 adapters (Figure 1). The T7TOPO oligonucleotide contains the sequence of the phage $\mathrm{T} 7$ promoter at its $5^{\prime}$ end and a recognition site for vaccinia DNA topoisomerase I within nine bases of its $3^{\prime}$ end. The ASTOPO oligonucleotide performs a supporting role in the hybrid molecule by forming dsDNA from its complementary sequence to T7TOPO. The symmetric hybrid has two topoisomerase recognition sites and two nicks.

During activation, the topoisomerase cleaves T7TOPO at the recognition site and covalently binds to the last deoxythymidine in the recognition site through its 3 ' phosphate (Figure 1). The new complex is relatively stable for months when stored at $-20^{\circ} \mathrm{C}$ in $50 \%$ glycerol. The topoisomerase may transfer this covalent bond to the $5^{\prime}$ hydroxyl group of the acceptor when incubated with PCR products if they were amplified with unphosphorylated primers and have a 3'-end A-overhang. Thus, 26 bases of the T7TOPO oligonucleotide, including the T7 promoter, are ligated to each strand of the PCR products. The promoter sequence may be secured to either end of the PCR product by reamplifying with $\mathrm{T} 7$ primer and sense or antisense gene-specific primer.

Two PCR products were used as a model for the incorporation of $\mathrm{T} 7$ promoters: fragments of red/green cone pigment cDNAs amplified from monkey retina and a fragment of the human PRL-1 gene amplified from genomic
DNA. The final products were sequenced using $\mathrm{T} 7$ or gene-specific primers and were found to have the $\mathrm{T} 7$ promoter sequence on one end (data not shown). Incorporation of the $\mathrm{T} 7$ promoter sequence into PCR products was also demonstrated on an agarose gel (Figure 2). The templates for IVT of the red/green pigment cRNA probe, reamplified with the $\mathrm{T} 7$ promoter and either sense or antisense primer after the reaction with the adapters, were clearly longer than the original fragment of the red/green cone pigment cDNA. In the case of the fragment of the PRL-1 gene, the increase in the length of PCR products by 26 bp is only $5 \%$ of its length; nevertheless, this difference can still be observed. These data on fragment electrophoretic mobility and the sequencing

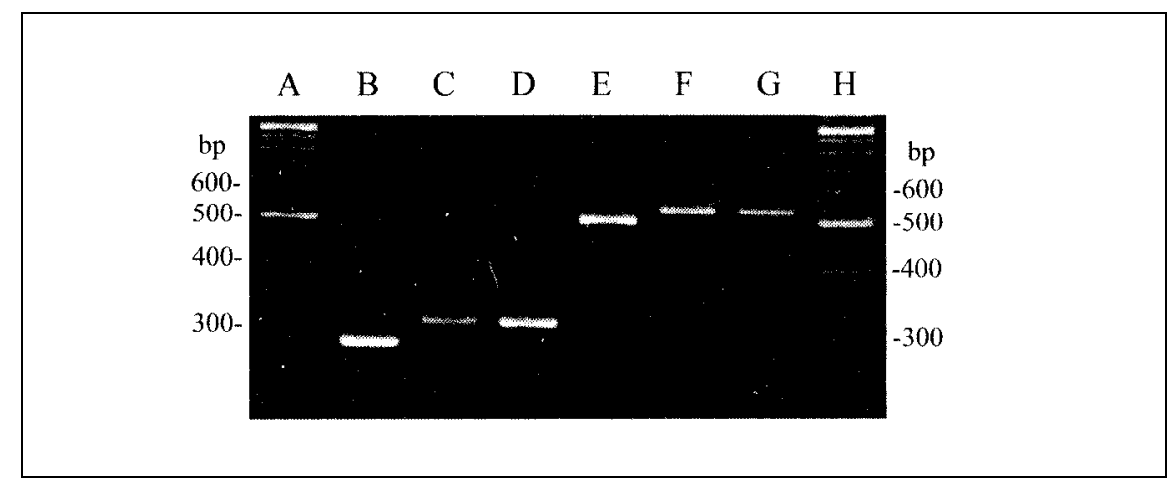

Figure 2. Incorporation of $\mathrm{T} 7$ promoters into PCR products may be monitored by changes in electrophoretic mobility. Products of PCR amplification from retinal cDNA (288-bp fragment of red/green cone pigment cDNA, lane B) and genomic DNA (481-bp fragment of PRL-1 gene, lane E) were used to incorporate $\mathrm{T} 7$ promoters with topoisomerase-activated adapters. T7 promoters were secured to either the $5^{\prime}$ or $3^{\prime}$ ends after reamplification in separate reactions with $\mathrm{T} 7$ primer and gene-specific primers. The resulting templates for in vitro transcription migrate slower than the original PCR products: red/green cone pigment antisense (lane C) and sense (land D); PRL-1 anti-sense (lane F) and sense (lane G). A 100bp ladder is shown in lanes $\mathrm{A}$ and $\mathrm{H}$.

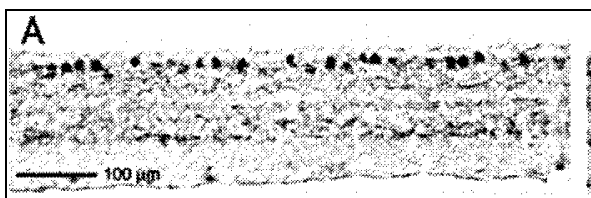

B

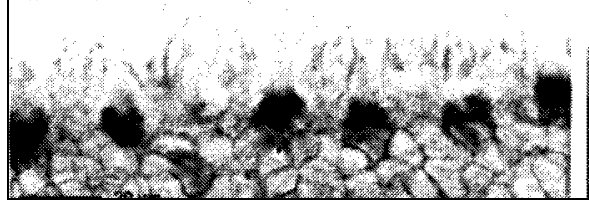

Figure 3. In situ hybridization of monkey retina sections with antisense and sense red/green pigment cRNA probes transcribed from PCR products containing T7 promoters. Monkey retina was hybridized with DIG-labeled cRNA probe for red-green cone pigment. The antisense probe labels inner segments of the majority of cone photoreceptors (A,B), while the sense probe gave no signal (C,D). The scale is $100 \mu \mathrm{m}$ [(A,C) or $20 \mu \mathrm{m}(\mathrm{B}, \mathrm{D})]$ OS, outer segments; IS, inner segments; ONL, outer nuclear layer; INL, inner nuclear layer; GCL, ganglion cell layer.

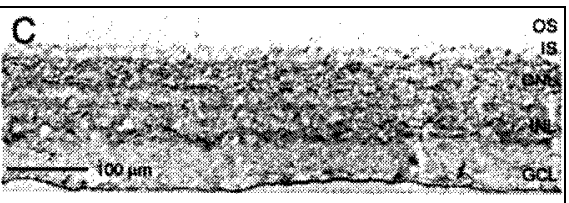

1

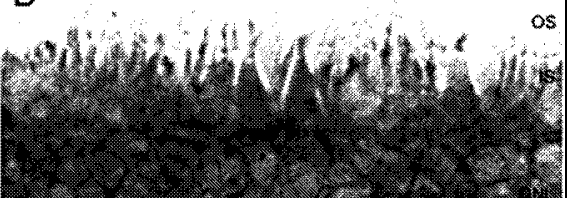


results provide evidence that the $\mathrm{T} 7$ promoters are secured only on one end of the final PCR products, which is important for specific synthesis of antisense or sense cRNA probes.

The PCR products containing the T7 promoter were shown to be functionally active as templates for IVT using phage T7 RNA polymerase. The yields of $20-\mu \mathrm{L}$ reactions, estimated by dot blotting with anti-DIG antibodies conjugated to alkaline phosphatase, were in the range of 2-5 $\mu \mathrm{g}$ DIG-labeled cRNA (data not shown).

The synthesized riboprobes for the red/green cone pigment cDNAs were used for in situ hybridization of monkey retina tissue (Figure 3 ). The antisense probe showed strong specific binding to the majority of the cones. The signal was localized to the inner segments of the cones with lower staining in the nucleus and perinuclear regions. The distribution and pattern of staining were similar to the labeling of Macaca retina with an antisense probe for long or medium wavelength-sensitive opsins (1). Control slides hybridized with the sense probe gave no specific labeling in any cells.

The data presented here demonstrate that topoisomerase-activated adapters may be used to incorporate functional T7 promoters into PCR products. This significantly simplifies the generation of cRNA probes for a known sequence: instead of subcloning in plasmid vectors or synthesizing primers containing RNA polymerase promoters at the $5^{\prime}$ ends of each DNA of interest, universal T7 adapters may be used to perform IVT from PCR products using T7 RNA polymerase. If another RNA polymerase is preferred, topoisomerase-activated adapters carrying SP6 or T3 promoters may be generated. If needed, the adapters may be made to facilitate reactions with blunt-end PCR products amplified by proofreading DNA polymerases. Moreover, virtually any sequence may be added to PCR products with properly designed topoisomeraseactivated adapters, making them a versatile tool for molecular cloning.

\section{REFERENCES}

1.Bumsted, K., C. Jasoni, A. Szel and A. Hendrickson. 1997. Spatial and temporal expres- sion of cone opsins during monkey retinal development. J. Comp. Neurol. 378:117-134.

2.Chirgwin, J.M., A.E. Przybyla, R.J. MacDonald and W.J. Rutter. 1979. Isolation of biologically active ribonucleic acid from sources enriched in ribonuclease. Biochemistry 18:5294-5299.

3.Grünewald-Jahno, S., J. Keesey, M. Leous, R. van Miltenburg and C. Schroeder (Eds.). 1996. Nonradioactive In situ Hybridization. Application Manual. Second edition. Roche Molecular Biochemicals, Mannheim, Germany.

4.Heyman, J.A., J. Cornthwaite, L. Foncerrada, J.R. Gilmore, E. Gontang, K.L. Hartman, C.L. Hernandez, R. Hood et al. 1999. Genome-scale cloning and expression of individual open reading frames using topoisomerase I-mediated ligation. Genome Res. 9:383-392.

5.Logel, J., D. Dill and S. Leonard. 1992. Synthesis of cRNA probes from PCR-generated DNA. BioTechniques 13:604-610.

6.Melton, D.A., P.A. Krieg, M.R. Rebagliati, T. Maniatis, K. Zinn and M.R. Green. 1984. Efficient in vitro synthesis of biologically active RNA and RNA hybridization probes from plasmids containing a bacteriophage SP6 promoter. Nucleic Acids Res. 12:7035-7056.

7.Shuman, S. 1991. Site-specific interaction of vaccinia virus topoisomerase I with duplex DNA. J. Biol. Chem. 266:11372-11379.

8.Shuman, S. 1992. DNA strand transfer reactions catalyzed by vaccinia topoisomerase I. J. Biol. Chem. 267:8620-8627.

9.Shuman, S. 1994. Novel approach to molecular cloning and polynucleotide synthesis using vaccinia DNA topoisomerase. J. Biol. Chem. 269:32678-32684.

The author thanks Dr. Cathy Bowes Rickman for her support of this study, Drs. Donald Heistad and Donald Piegors for generously providing monkey tissue and Dr. Robert Nickells for helpful consultations on protocols for in situ hybridization. The author also thanks Elena D. Kallestinova for her assistance in preparing the manuscript. Address correspondence to Dr. Timur O. Yarovinsky, University of Iowa, Department of Ophthalmology and Visual Sciences, 2501 Crosspark Rd., B141 MTF, Coralville, IA 52241, USA. Internet: timur-yarovinsky@uiowa.edu

Received 1 December 1999; accepted 22 February 2000.
Timur O. Yarovinsky
The University of Iowa
Iowa City, IA, USA 